\title{
Determining bicycle infrastructure preferences - A case study of Dublin
}

\author{
Brian Caulfield ${ }^{1,}$ Elaine Brick ${ }^{2}$, Orla Thérèse McCarthy ${ }^{1}$ \\ ${ }^{1}$ Department of Civil, Structural and Environmental Engineering, Trinity College \\ Dublin, Dublin 2, Ireland \\ ${ }^{2}$ AECOM, Grand Canal House, Upper Grand Canal Street, Dublin 4, Ireland
}

\begin{abstract}
This paper examines infrastructure preferences for cyclists. In Ireland, the Irish National Cycle Policy Framework acknowledges that investment in cycling infrastructure type and quality has been 'in many cases, inadequate' and has, generally, not led to an overall increase in cycling numbers. Therefore, in order to ensure future investment is targeted where it is likely to be most effective in achieving adopted mode share targets for cycling, the following research has been undertaken to determine the factors which most influence cycling route choice. In particular, the research aims to determine the factors, which have greatest influence on cycle route infrastructure preference the correlation between the level of cycling confidence and preferred types of infrastructure and route characteristics.

A stated preference survey, undertaken by almost 2,000 cyclists and noncyclists, was used to gauge preferences for a range of infrastructure types and route characteristics. Facilities which were segregated from traffic were the most preferred form of cycling infrastructure, regardless of cycling confidence. Interestingly, routes through residential streets and parks were the second most favoured, where no specific infrastructure is provided with the exception of improvements in way-finding. Routes which offered no facilities were least favoured and least likely to support a shift to cycling.
\end{abstract}

\section{Introduction and background}

Transport policy across Europe in the past ten years has made a significant shift to sustainable transport objectives and targets which are clearly linked to environmental and economic objectives. In Ireland, Smarter Travel, the National Sustainable Transport Policy marks a significant departure from previous national policies for transport. This plan has a greater focus to strengthening Ireland's road and public transport networks (Department of Transport, 2009a). The strategy highlights the implications of future growth projections on the Irish transport network: increasing car ownership and annual vehicle kilometres travelled, declining average speeds in commuting periods and increasing congestion amidst a decline in walking and cycling modal share. In light of these forecasts, the strategy sets out bold travel targets supported by a 48 actions for implementation, ranging from infrastructure to policy and education measures. The overall target is to reduce work related commuting by car from a current modal share of $65 \%$ to $45 \%$. In addition, it is envisaged that total 
vehicle kilometres travelled by car will not increase substantially from a 2009 baseline (Department of Transport, 2009a).

These targets are challenging and highlight the need for a robust response in terms of policy and investment. The Strategy therefore sets out separate objectives and targets for walking, cycling and public transport. In relation to cycling, the Strategy aims to secure a 'strong culture of cycling in Ireland and ensure that all cities, towns, villages and rural areas will be cycle-friendly' (Department of Transport, 2009a). The strategy envisages that by $2020,10 \%$ of all our trips will be by bike. In relation to commuting, the Strategy envisages that by 2020 cycle trips to work will have increased to 160,000 from a 2006 baseline of 35,000.

To encourage delivery of the Smarter Travel vision, the National Cycle Policy Framework was adopted in 2009 (Department of Transport, 2009b). The Framework is clear on the challenges, which lie ahead by acknowledging that investment in cycling infrastructure has been inadequate and has not led to an overall increase in cycling. The Framework presents a robust package of measures classified into the following categories: Planning, Infrastructure, Communication and Education.

With regards infrastructure design, the National Cycle Policy Framework also reiterates the need for transportation infrastructure design to be 'cycle friendly'. 'Cycle friendly' routes are defined as those that are deemed to be: safe, direct, coherent, attractive and comfortable. These five criteria frequently form the basis of cycling infrastructure policies internationally and are also identified in the National Cycle Manual (National Transport Authority, 2011) as being the five 'basic needs' of cyclists which should be understood by designers if 'cycle friendly' environments are to be created.

\section{Methodology}

\section{Stated Preference Model}

The stated preference experiments used for this research included a route choice model which examined 5 key attributes. Table 1 outlines each of the attributes and attribute levels examined. These determinants were proposed on the basis of local knowledge of the local transport network as well as outputs from the literature review.

\section{$<<$ INSERT TABLE $1>>$}

The infrastructure options presented are highlighted in Figure 1. These options were based on the five most common cycle route infrastructure types in the Greater Dublin area.

\section{$<<$ INSERT FIGURE $1>>$}

A fractional factorial was designed which included two routes each which had the same attributes but differed on the attribute levels. A fractional factorial was designed using the method described in Hensher et al (2005). The fractional factorial design produced 64 scenarios to be evaluated. These scenarios were randomly distributed to 11 versions of the survey, with 10 versions of the survey containing 6 scenarios to evaluate and 1 with 4 scenarios.

As the respondents may not be familiar with the variants of cycle lane presented in the scenarios, it was decided to make these scenarios as visual as 
possible. An example of one of the scenarios is shown in Figure 2. The following text was used to set up the scenarios presented to the respondents.

"You have started a new job, which is located close to your home. Cycling to work has now become a possibility. Whether you currently cycle to work or not, please consider the following route choices for your trip to work and choose the most preferable route for your journey to work in each instance".

$<<$ INSERT FIGURE 2 $>>$

A multinomial logit model was used to estimate the impact of each of the attributes presented in Table 1. The model takes the following functional form:

$U_{i n}=X_{i n}+{ }_{i n}$

where $n$ represents the route choice option and $i$ represents the individual. $X_{i n}$ represents the set of explanatory variables specific to route option $n$ and by individual $i$. $U_{\text {in }}$ is the utility obtained by individual $i$ and $\varepsilon_{\text {in }}$ is a random error term, which is assumed to be identically and independently distributed using the Gumbel distribution method (Train, 2003).

The probability that individual $i$ chooses route $n$ can be expressed as follows:

$\operatorname{Prob}\left(U_{i n}>U_{j n}\right)=\frac{e^{X_{i n}}}{\left(e^{X_{i n}}+e^{X_{j n}}\right)}$

The above equation states that the individual will choose route $n$ over the other route (j) providing the utility that's derived from this route is greater than the alternative route. The models estimated using a maximum likelihood estimation approach (Hensher et al 2005; Train, 2003 or Louviere et al 2000 for more details on this approach). Several models are presented in the next section, some of the models have been segmented by various attributes such as gender, age etc. The models were segmented to provide an indication as to how various characteristics of the respondents' impact upon their route choice selection.

\section{Data collection}

The survey was undertaken by 1,941 people employed in businesses participating in the Smarter Travel Workplaces initiative, currently being managed by the Irish National Transport Authority. The businesses are all located within an $8 \mathrm{~km}$ radius of the city centre.

\section{Results}

\section{Descriptive results}

Table 2 presents descriptive results of the sample collected. The gender balance of respondents was relatively balanced, $51.8 \%$ male and $48.2 \%$ female. $45.7 \%$ of respondents were in the $25-34$ age group and $26.1 \%$ in the $35-44$ age group. $51.8 \%$ of the sample was shown to have one car and $31.2 \%$ had two cars in their household. 
The results for mode of transport used to travel to work showed that just under $30 \%$ of the sample drove alone on a regular basis to work. $14.9 \%$ indicated they walked and $18.1 \%$ said they cycled to work on a regular basis. The final result presented in Table 2 details the distance travelled to work. $9 \%$ travelled less that $2 \mathrm{~km}$ and $21.8 \%$ travelled $3-5 \mathrm{~km}$.

In terms of how the sample relates to the national population, the gender split was generally representative of the national population. There was a bias in this survey towards those in the working age cohort of 25-34. In terms of the mode of travel to work, sustainable transport modes are generally better represented. This is due to the fact that the survey respondents were generally living in the Dublin urban area where there are greater bus and rail options and where even networks to support walking and cycling are better established than in other parts of the country. With regards cycling for example, $18 \%$ of respondents cycle to work while nationally this figure is just $4 \%$ as recorded in the 2006 Census.

\section{$<<$ INSERT TABLE 2>>}

Before the stated preference component of the survey was presented to respondents, they were asked to indicate what factors would encourage the respondents to begin cycling. The results from this question can are presented in Table 3. 74.1\% of respondents said more off road cycle tracks and $56.4 \%$ said that more connected onroad cycle lanes would encourage them to begin to cycle to work. The results for better facilities at work, better signage, improved information and increased bike parking were found to be unlikely to encourage individuals to cycle to work. Interestingly $69.1 \%$ of respondents said less traffic was unlikely to encourage them to cycle on a regular basis.

\section{$<<$ INSERT TABLE $3>>$}

In the survey respondents were asked how confident they were cycling in Dublin. The results show that $14.8 \%$ indicated that they were completely confident and $20.1 \%$ said they were very confident (see Table 4). The respondents were also asked had cycle safety changed in Dublin in the past three years. $8.7 \%$ said safety had improved a lot and $59.4 \%$ said that it has improved slightly.

\section{$<<$ INSERT TABLE 4>>}

\section{Route choice models}

This section of the paper presents the results from the route choice models. The first model presented in Table 5 contains the results of the base model, which includes all of the respondents in the sample. The first set of coefficients examines the impact adjacent traffic speed has upon route choice. The findings show that respondents had a greater preference for lower adjacent traffic speeds as the $30 \mathrm{~km}$ per-hour coefficient has the highest positive value. The second set of coefficients measure the impact that the cycle route type has upon route choice. The results show that both the 'cycle/bus lane' and the 'no-lane' options both had significant negative coefficients indicating that respondents are unlikely to select a route option if it has this type of route infrastructure. The 'off road cycle lane' option was found to have the highest positive 
coefficient followed by the 'greenway' option, this result indicates that respondents are more likely to choose a route that has one of these infrastructures.

The results for the travel time coefficients show, as one would expect, that respondents had a greater preference for lower travel times, with the coefficient related to a 10-minute travel time having the highest positive coefficient. The number of junctions that the respondent would encounter while cycling along the route was examined to determine if this would significantly impact upon respondents' utility. The findings show that respondents are more likely to choose a route that has fewer junctions with the 'less than 2 junctions' coefficient having the highest positive value. The final set of coefficients presented in Table 5 relates the amount of cycle traffic along the route. The findings show that respondents have a slight preference for light traffic while cycling along the route.

\section{$<<$ INSERT TABLE $5>>$}

The model results presented in Table 6 segment the route choice model by the users cycling confidence level. The dataset was segmented by the five confidence levels reported in the survey, ranging from 'completely confident' to 'not at all confident'. The first set of results relate to the 'adjacent traffic speeds'. The results show no clear pattern amongst the different groups other than the fact that all groups do have a preference for lower traffic speeds. However, as one would expect those in the 'not at all confident' group where shown to have the greatest preference for lower speeds. The findings for the type of cycling infrastructure show that, again as one would expect, those with lower confidence levels would derive the greatest benefit from 'greenways' and 'off road cycle lanes'.

The findings for the travel time showed that there was very little difference between the user groups, but that all respondents had a desire for lower travel times. The findings for the number of junctions encountered along the route showed that those respondents that were 'not at all confident' cyclists were shown to have the greatest preference for lower numbers of junctions along the route. The final set of results presented in Table 6 estimate the impact that the volume of cycling traffic has along the route. The findings suggest that those respondents with lower levels of cycling had a greater preference for lower traffic volumes along the route.

$<<$ INSERT TABLE $6>>$

\section{Summary of findings}

The purpose of this research was to add further clarity in relation to individual preference regarding infrastructure and the measures which are most likely to achieve modal shift. An improvement in infrastructure for cyclists is the most important measure in encouraging a growth in cycling. This is followed by the need for increased bike parking and better facilities for cyclists such as showers and lockers at work.

Direct routes with short journey times were found to be the most important variable for existing cyclists and non-cyclists in determining route choice. This is followed by infrastructure type, the number of junctions along the route, traffic speed and cyclist volumes. In terms if infrastructure, regardless of the level of cycling confidence, routes which have 'no facilities' or 'bus/cycle lanes' are the least favoured cycle route types. 
There appears to be no direct correlation between cycling confidence and route choice preference with confident cyclists demonstrating a similar preference for the presented infrastructure types as respondents with no cycling confidence. There are, however, a small proportion of very confident cyclists who place high importance on short journey times and direct facilities with low cyclist volumes. For these cyclists, type of infrastructure and traffic speeds is of less relevance.

\section{Acknowledgments}

The authors wish to thank the National Transport Authority and Dublin City Council for their assistance in undertaking this research.

\section{References:}

Department of Transport, Smarter Travel: A New Transport Policy for Ireland 20092020, Dublin, Ireland, 2009a

Department of Transport, Ireland's First National Cycle Policy Framework, Dublin, Ireland, 2009b

Hensher, D. A., Rose, J.M. and Greene, W.H. Applied Choice: A Primer. Cambridge University Press, New York, 2005.

Louviere, J. J., Hensher, D.A., J.D. Swait. J.D, Stated Choice Methods: Analysis and Application, Cambridge University Press, 2000.

National Transport Authority, National Cycle Manual, Dublin, Ireland, 2011

Train. K. Discrete Choice Methods wit Simulation, Cambridge University Press, New York, 2003 
Figure 1

Click here to download high resolution image

Figure 1 Cycling infrastructure choices used within the route choice model

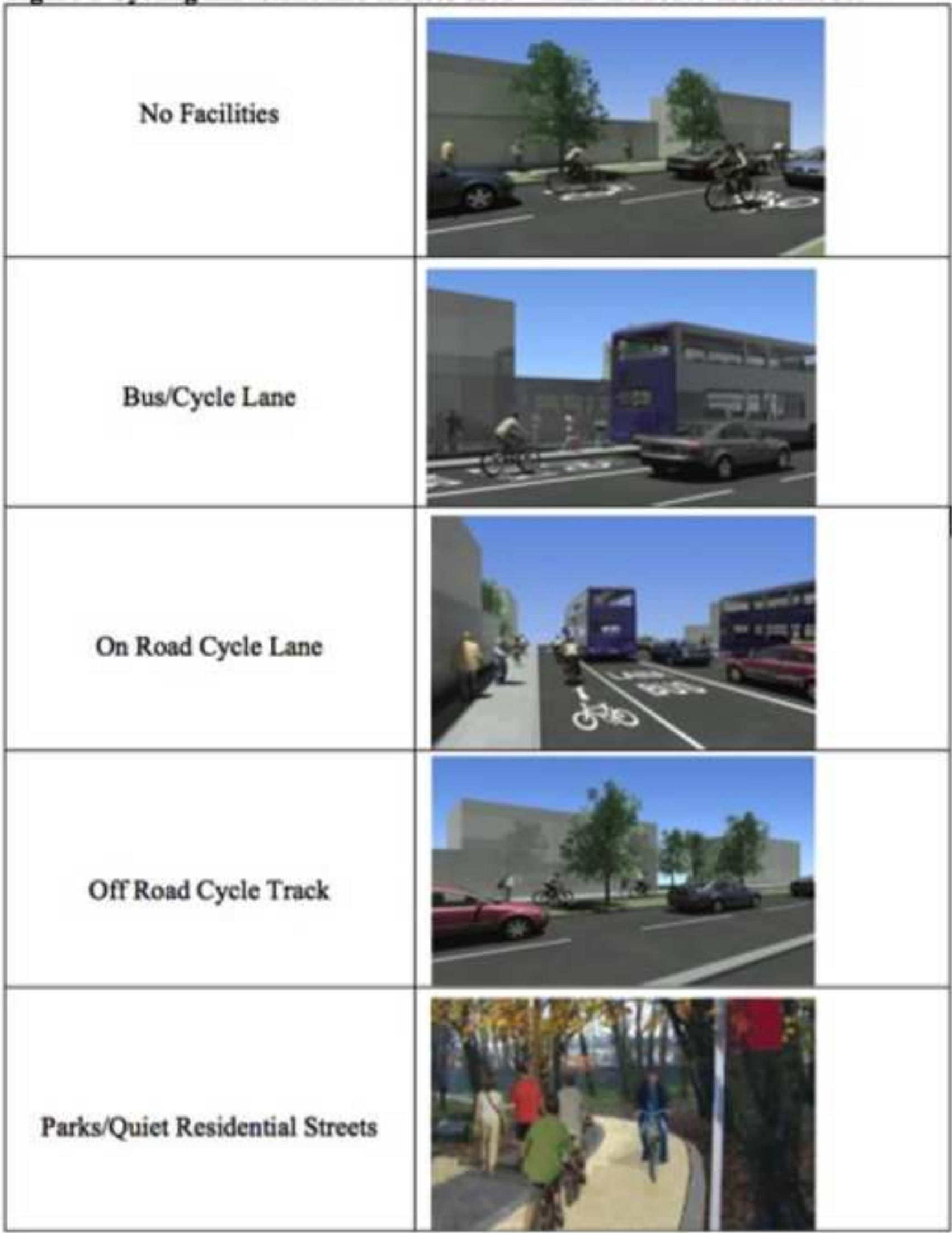




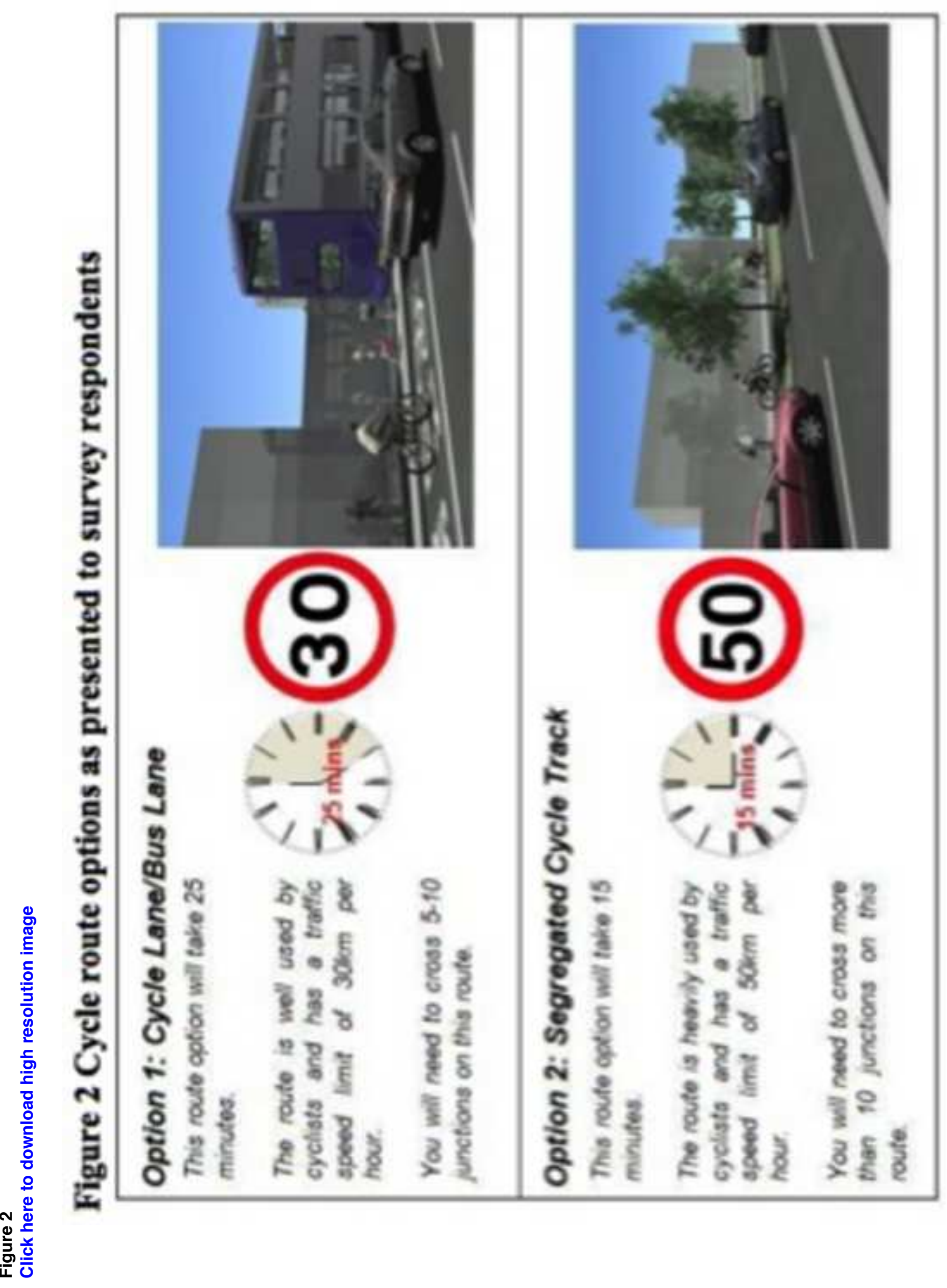




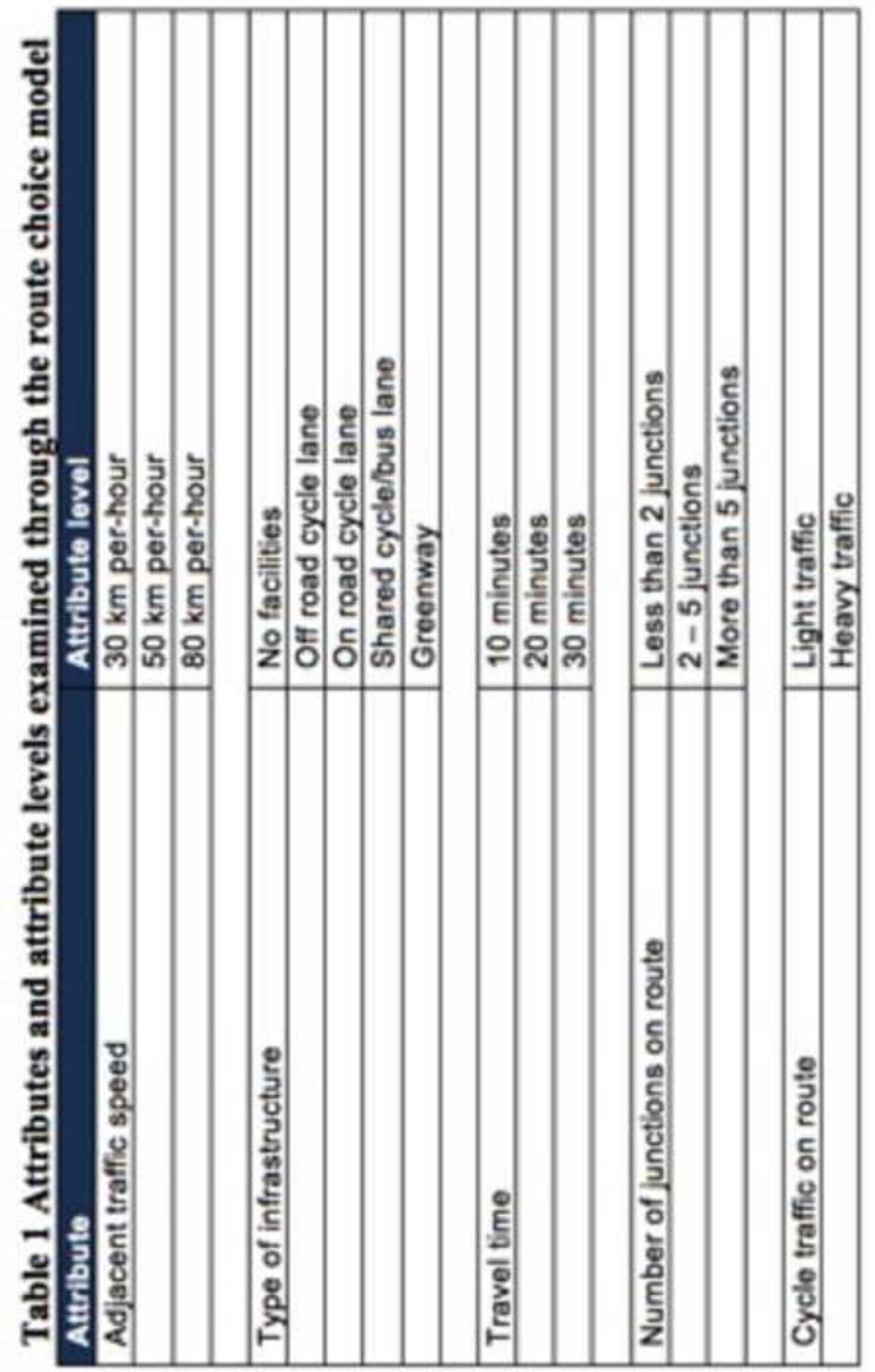


Table 2

Click here to download high resolution image

Table 2 Descriptive results

\begin{tabular}{|c|c|c|}
\hline Gender & $\mathrm{N}$ & $\%$ \\
\hline Male & 1006 & 51.8 \\
\hline Female & 935 & 48.2 \\
\hline Total & 1941 & 100 \\
\hline \multicolumn{3}{|l|}{ Age } \\
\hline $18-24$ & 203 & 10.5 \\
\hline $25-34$ & 888 & 45.7 \\
\hline $35-44$ & 507 & 26.1 \\
\hline $45-54$ & 252 & 13.0 \\
\hline $55-64$ & 87 & 4.5 \\
\hline $65+$ & 4 & 2 \\
\hline Total & 1941 & 100.0 \\
\hline \multicolumn{3}{|c|}{ Number of cars per household } \\
\hline No car available & 244 & 12.6 \\
\hline 1 & 1006 & 51.8 \\
\hline 2 & 605 & 31.2 \\
\hline $2+$ & 86 & 4.4 \\
\hline Total & 1941 & 100.0 \\
\hline \multicolumn{3}{|c|}{ Mode of transport used to travel to work } \\
\hline Walk & 289 & 14.9 \\
\hline Cycle & 351 & 18.1 \\
\hline Bus & 265 & 13.7 \\
\hline Rail & 358 & 18.4 \\
\hline Car - driver & 569 & 29.3 \\
\hline Car - passenger & 74 & 3.8 \\
\hline Motorcycle & 33 & 1.7 \\
\hline Work from home & 2 & 1 \\
\hline Total & 1944 & 100.0 \\
\hline \multicolumn{3}{|c|}{ Distance travelled to work } \\
\hline $0-2 \mathrm{~km}$ & 175 & 9.0 \\
\hline $3.5 \mathrm{~km}$ & 423 & 21.8 \\
\hline $6.9 \mathrm{~km}$ & 462 & 23.8 \\
\hline $10-15 \mathrm{~km}$ & 444 & 22.9 \\
\hline $16 \mathrm{~km}+$ & 437 & 22.5 \\
\hline Total & 1941 & 100.0 \\
\hline
\end{tabular}




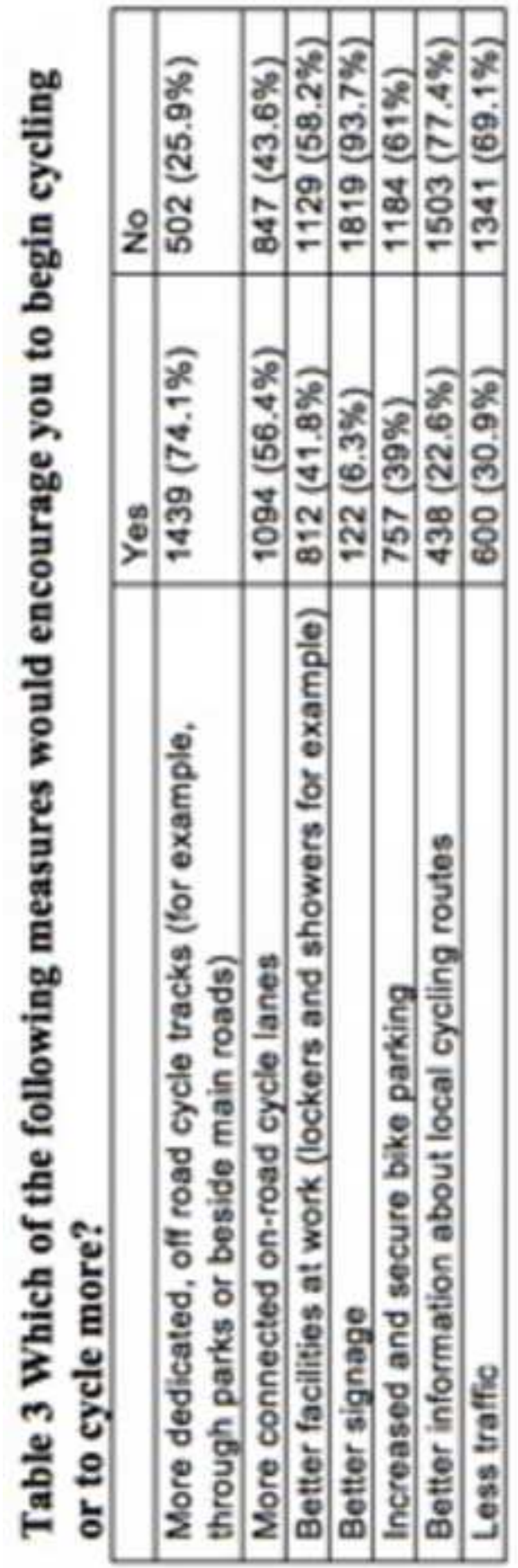




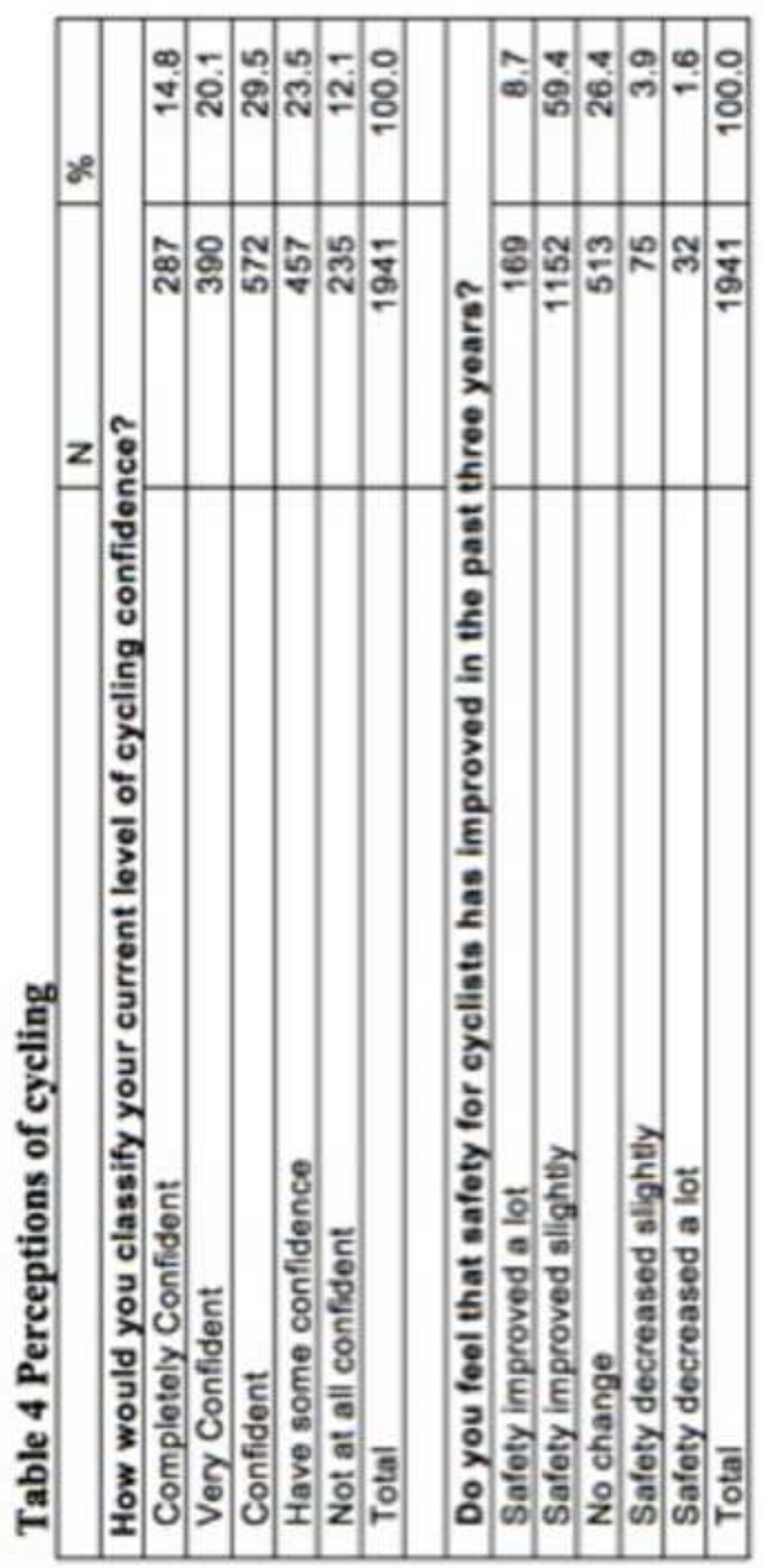

$+\stackrel{\Phi}{8}$

家 
Table 5

Click here to download high resolution image

Table 5 Base model and results segmented by gender

\begin{tabular}{|c|c|c|c|}
\hline & Base model & Male & Female \\
\hline Intercept & $-1.388^{*}$ & $-1.260^{* \bullet}$ & $-1.549^{* *}$ \\
\hline \multicolumn{4}{|c|}{ Adjacent Traffic Speed } \\
\hline $30 \mathrm{KM}$ per-hour & $.788^{* *}$ & $.635^{* *}$ & $.921^{* *}$ \\
\hline 50KM per-hour & $.535^{* *}$ & $.436^{\circ}$ & $611^{* *}$ \\
\hline 80KM per-hour & Ref & Ref & Ref \\
\hline \multicolumn{4}{|l|}{ Cycle Route Type } \\
\hline Cycle/bus lane & $-.792^{* *}$ & $-.844^{* *}$ & $-.736^{\circ}$ \\
\hline Greenway & $202^{*}$ & $.146^{\circ}$ & $.346^{* *}$ \\
\hline No - lane & $-1.116^{* *}$ & $-1.060^{* *}$ & $-1.167^{* *}$ \\
\hline Off road cycle lane & $.449^{* *}$ & $.340^{* 0}$ & $.597^{* *}$ \\
\hline On-road cycle lane & Ref & Ref & Ref \\
\hline \multicolumn{4}{|l|}{ Travel Time } \\
\hline 10 minutes & $1.353^{* *}$ & $.923 *$ & $1.150^{* *}$ \\
\hline 20 minutes & $240^{\circ}$ & $.306^{* *}$ & $.230^{* *}$ \\
\hline 30 minutes & Ref & Ref & Ref \\
\hline \multicolumn{4}{|l|}{ Number of Junctions } \\
\hline Less than 2 junctions & $1.050^{* *}$ & $923^{* *}$ & $1.150^{* *}$ \\
\hline 2 to 5 junctions & $419^{* *}$ & $.306^{* *}$ & $.230^{* *}$ \\
\hline More than 5 junctions & Ref & Ref & Ref \\
\hline \multicolumn{4}{|l|}{ Cycle Route Traffic } \\
\hline Light traffic & $.083^{* *}$ & $.149^{* *}$ & $.044^{* *}$ \\
\hline Heavy traffic & Ref & Ref & Ref \\
\hline Number of cases & 11,692 & 5742 & 5298 \\
\hline$R$-squared & 262 & .270 & .262 \\
\hline Log likelihood & 983.34 & 786.43 & 456.09 \\
\hline
\end{tabular}

** Significant at $1 \%, *$ Significant at $5 \%$ 


\begin{tabular}{|c|c|c|c|c|c|c|c|c|c|c|c|c|c|c|c|c|c|c|c|c|}
\hline 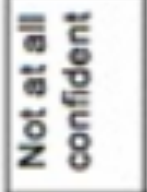 & $\frac{2}{\frac{2}{6}}$ & ํํำ & 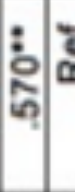 & 홈 & 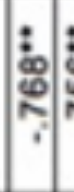 & 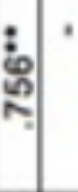 & ‘: & : & & 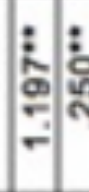 & స్. & & : & ฟै & & 웅. & ฮ্ & ફे & ฝิ & ڤ్ \\
\hline 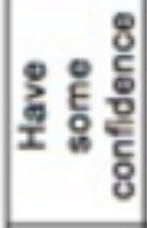 & ণิ & : & $\stackrel{2}{\grave{g}}$ & '্] & : & 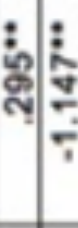 & $\frac{8}{5}$ & $\dot{\AA}$ & 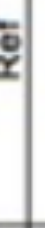 & 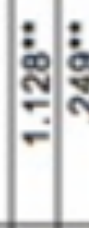 & ฟै. & & $\frac{\vdots}{5}$ & ষ্ণ & & ํํำ & 홈 & $\frac{n}{2}$ & ণุ & \\
\hline 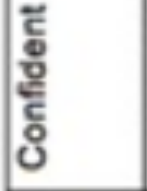 & 咅 & : & : & & : & 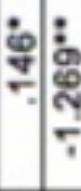 & $\frac{5}{2}$ & స్త్రి & है & 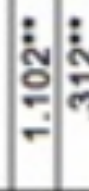 & $\frac{d}{c}$ & & : & : & & \%̊․ & $\bar{x}$ & $\frac{n}{\mathrm{~g}}$ & ฟิ & 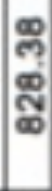 \\
\hline \: & : & 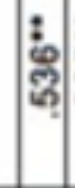 & প্লে & "ே. & : & $\stackrel{2}{2}$ & $\frac{\mathbb{Z}}{6}$ & ๙ิ & 包 & 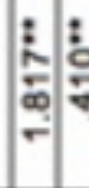 & $\frac{0}{8}$ & & $\frac{1}{\grave{d}}$ & 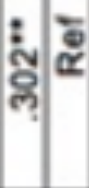 & & \%ุ & ฮ্ & ป & ฆิ & $\begin{array}{l}\bar{\infty} \\
\mathscr{\sigma} \\
0\end{array}$ \\
\hline 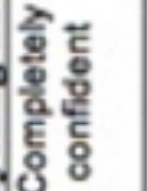 & 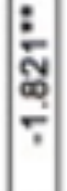 & $\frac{\mathfrak{t}}{\mathrm{\Phi}}$ & 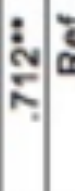 & 힘 & 웧 & 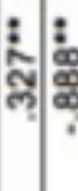 & : & ๙ู่ & & 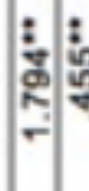 & : & & 영 & 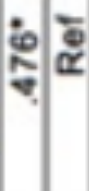 & & 章 & 홈 & 웅 & 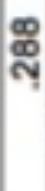 & 占 \\
\hline
\end{tabular}

